\title{
Amusement Park Physics in Panggon Lunjak (Trampoline): Analysis of Kinematics and Energy Use Video Tracking
}

\author{
Akhmad Yusuf ${ }^{1}$, Ishafit ${ }^{2}$, and Toni Kus Indratno ${ }^{3}$ \\ Laboratorium Teknologi Pembelajaran Sains, Program Studi Pendidikan Fisika, \\ Universitas Ahmad Dahlan. Jl. Prof. Dr. Soepomo, SH, Janturan, Warungboto, Umbulharjo, \\ Yogyakarta 55164, Indonesia
}

Yusuf.smart96@gmail.com¹, Ishafit@pfis.uad.ac.id², Tonikus@staff.uad.ac.id³

\begin{abstract}
Panggon Lunjak (trampoline) is one of the famous amusement parks among the people that we can use as a recreation to enjoy a pleasant sensation. Without us knowing the amusement park that we often encounter is actually the result of the application of science and technology, especially in the field of physics, because it is amusement park for student of science is a real laboratory or the giant laboratory that we can use as a study of physics concepts and as research materials. Panggon Lunjak (trampoline) motion is very close to the harmonic motion where the resulting graph of the sinus so that on the graph will be in the analysis of kinematics and energy phenomena, so that research on simple harmonic motion materials is not limited to research using pendulum motion and spring load motion which is often exemplified as research on harmonic motion. The purpose of this study is to analyze the physical aspects of Panggon Lunjak (trampoline) motion based on the laws of physics on the concept of kinematics and analyze energy, Where the mechanical energy of addition between potential energy and kinetic energy (Conservation of energy). The analysis is done by using video tracking. Based on the analysis done using people as a mass, the result of the amplitude, the spring constant, angular frequency, and the law of conservation of energy on the Panggon Lunjak (trampoline) is true. This analysis activity will be well used as a physics learning for students.
\end{abstract}

Keyword: amusement park physics, trampoline, kinematics, energy, video tracking

\section{Introduction}

Science learning, especially physics has been mostly done in the classroom [1]. It plays more with the threads of mathematical equations and only a little bit of physic concepts. Some of the learning is done in collaboration if the school has the means and approaches the school examination [1]. That's what causes physics is less desirable, even a frightening specter for students [2]. Physical learning is done in the classroom or the laboratory. Basically is no problem, and it should be like that. But it would be wise if students are invited to understand the application of concepts of physics in everyday life, for example, the application of the concept of physics in the amusement park recreation. This will undoubtedly reduce the saturation of students in studying physics. There are recreational places in a city that offer a variety of amusement park to bring their opportunities to analyze the physic concepts that exist there. One of them is 
trampoline rides (Panggon Lunjak). Trampoline is a giant gameplay that is elastic like a spring, which in a specific time can bring us feel up then down again and up again, and so on [3]. This activity of analysis or learning is called amusement park physics Whose purpose is to provide students with practice in applying some real physic concepts studied in the classroom especially in the subject matter of mechanics [4].

It is very clearly that these rides are elastic, bringing people up and down to apply the concept of harmonic motion. Harmonic motion is one of the subject matter of physics in high school [5]. Therefore, this research tries to give an idea how to prove the concept of physics in one of the game rides with a simple method and fun method. The students can be invited to the place of recreation to retrieve human motion data that ride trampoline rides. The data can be in the form of video, photos, or real time data using motion sensors that exist in their smartphones [6]. In this research focus on data analysis using video tracking.

\section{Research methods}

In this study using video tracking method, data obtained from the tracking of the motion of objects that have been recorded. Using Tracker software will get the data in form of position and time. Figure 1 is an example of a video that will be tracked using Tracker.

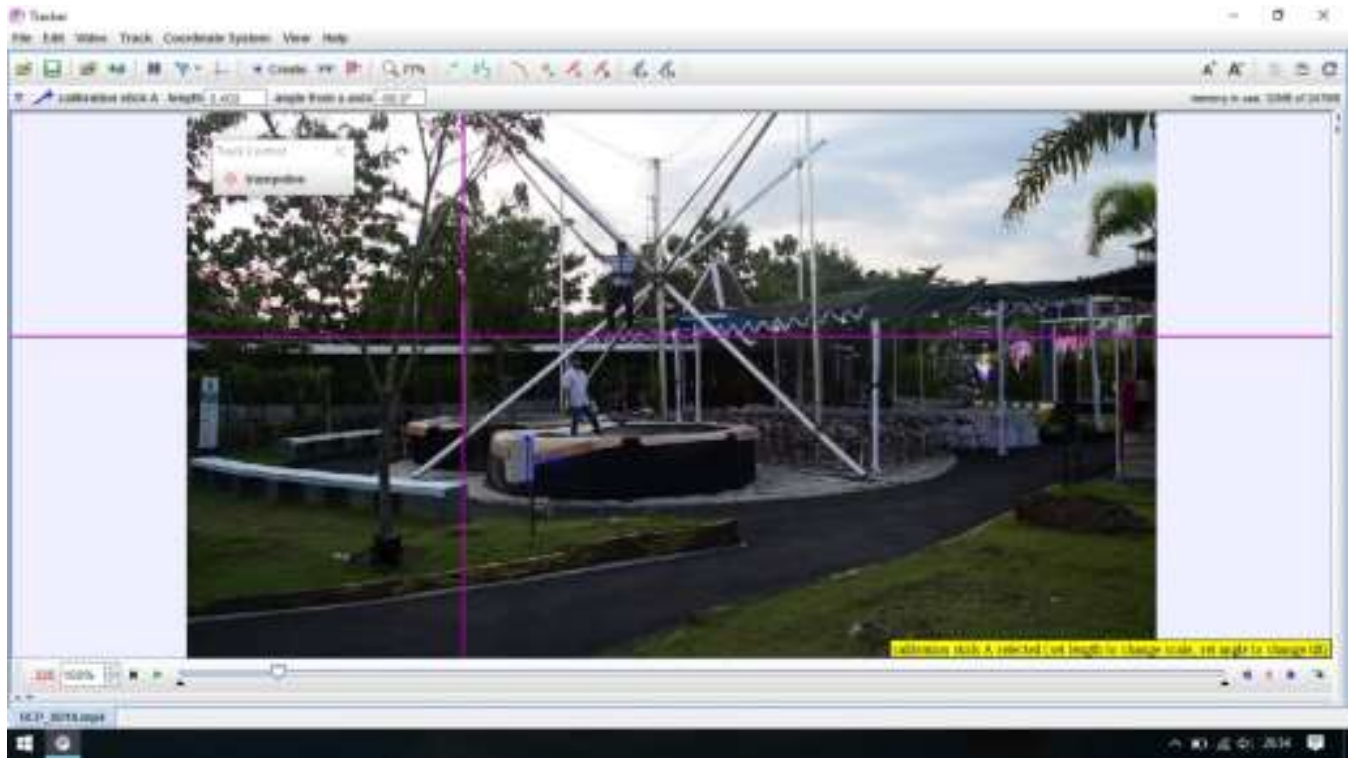

Figure 1. Trampoline rides that will be tacking using Tracker software

In this research trampoline video taken at the recreation Sindu Kusuma Edupark (SKE) Yogyakarta. A new recreation place in the middle of Yogyakarta City. Trampoline in SKE is called Panggon Lunjak [7].

More clearly this research is illustrated using a flow chart as shown in Figure 2. 


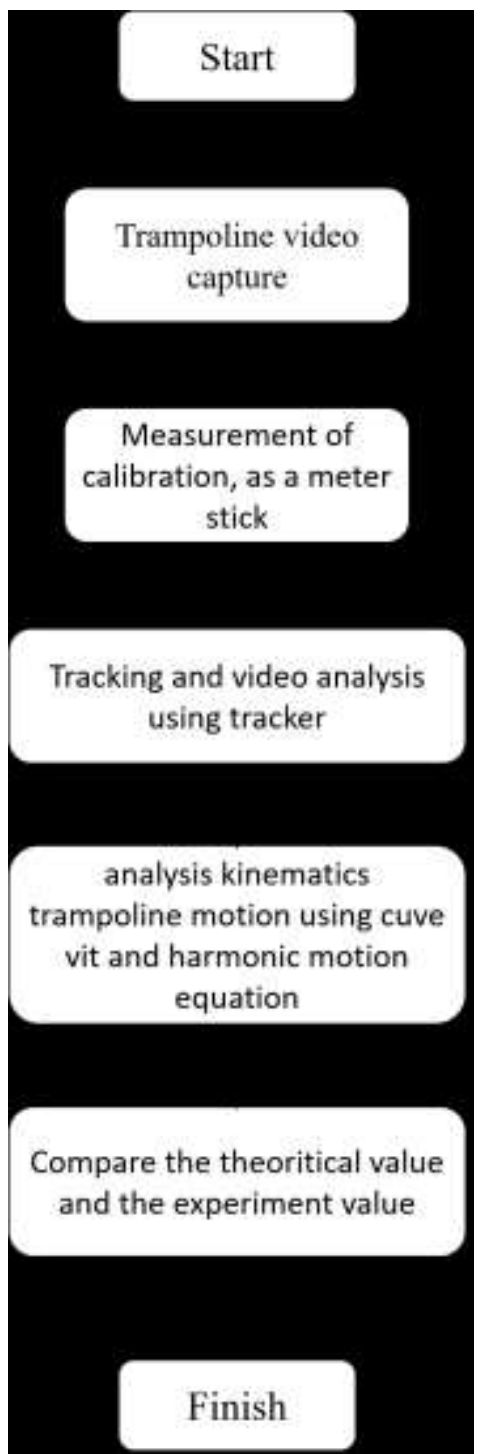

Figure 2. Flow Diagram of Video Tracking Analysis

Video tracking using Tracker will produce data in the form of graph relationship between the position y axis with time $t$ and people who mean as mass. Conducted data analysis to determine the value of amplitude, spring constant, angular frequency, period and the law of conservation of energy. The motion of the trampoline rides is very closely related to the harmonic motion. So to analyze the motion of the ride trampoline are using simple harmonic motion equations.

Solution of equations of harmonic motion [8]

$$
y(t)=A \sin (\omega t+\theta)
$$

to determine the value of the spring constant [9]

$$
\omega^{2}=\frac{k}{m}
$$

so that 


$$
k=\omega^{2} m
$$

while for energy conservation law on the harmonic motion [10]

$$
E_{M}=E_{P}+E_{K}
$$

with the value

$$
\begin{aligned}
& E_{P}=\frac{1}{2} k y^{2} \\
& E_{K}=\frac{1}{2} m v^{2} \text { or } E_{K}=\frac{1}{2} k\left(A^{2}-y^{2}\right)
\end{aligned}
$$

(6)

$$
E_{M}=\frac{1}{2} k A^{2}
$$

$E_{P}$ is Potential energy, $E_{K}$ is Kinetic Energy, and $E_{M}$

\section{Results and Discussion}

From the results of recording trampoline vehicle data in several times harmonic motion by using calibration size of stick $0.4 \mathrm{~m}$, mass people is $71 \mathrm{~kg}$ and than the people tracking with point mass tools. The tracking results in position and time, as shown in Figures 3 and Figure 4

In Figure 3 Explains for human motion on the trampoline with two jumps so that the resulting graph has two amplitudes as shown in figure 3 and so we can analyze it by using one-time jump which graph is displayed in Figure 4.

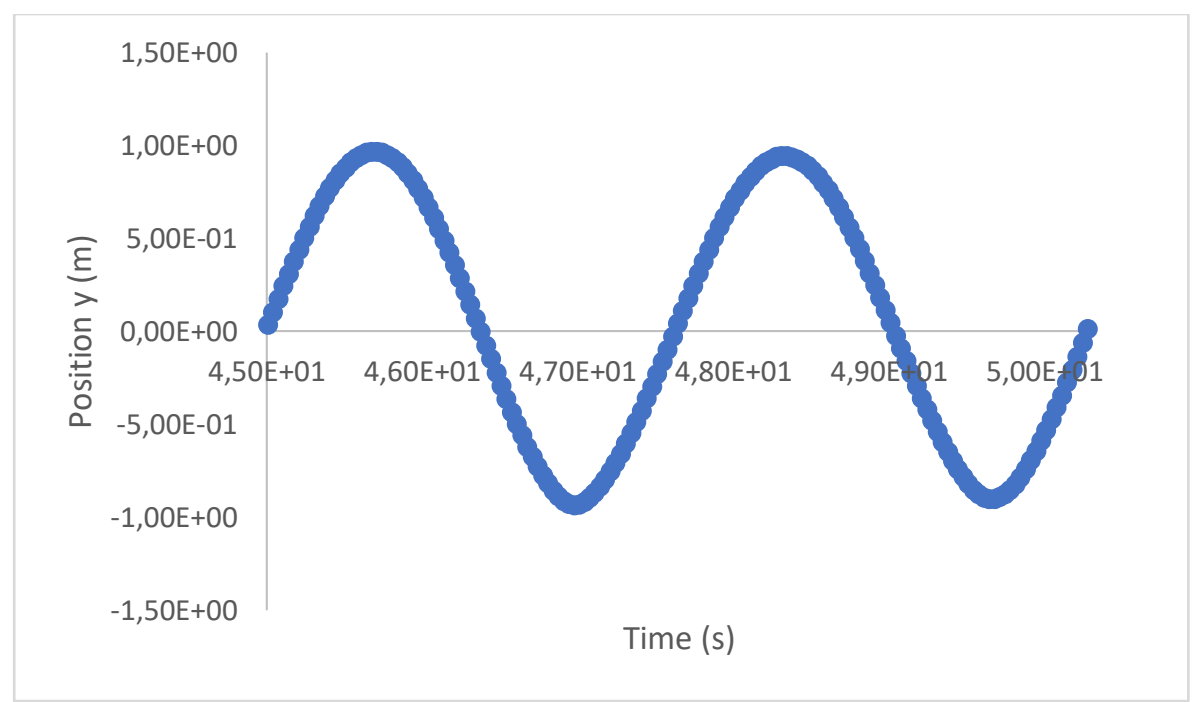

Figure 3. The graphed relationship between time and position y in two-time jumps 


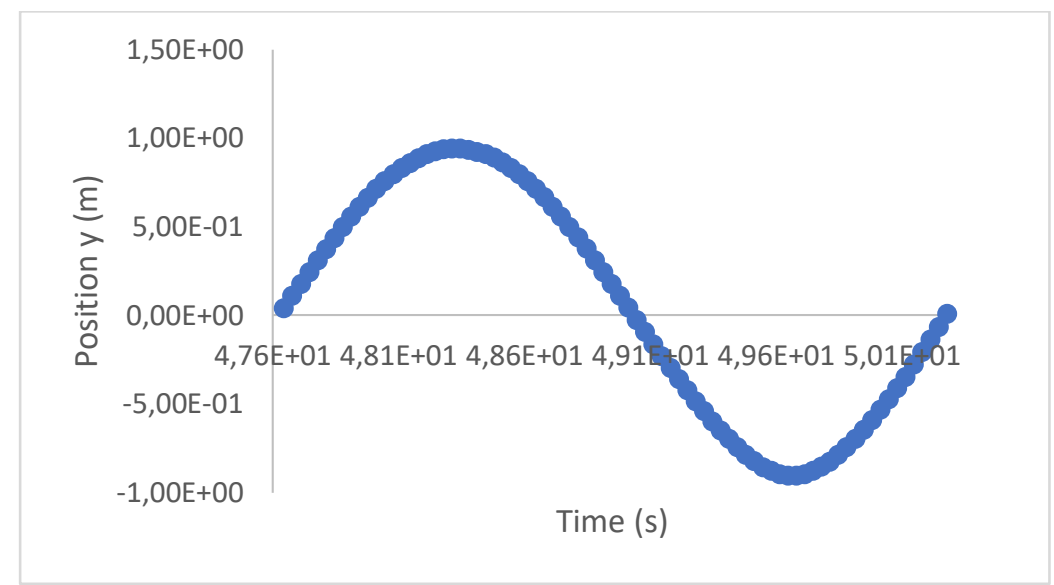

Figure 4. The graphed relationship between time and position y in once jump

From the data matching results in Figure 3 and Figure 4 using the curve fit analysis of obtained amplitude and angular frequency, frequency, and period are $0.9169 \mathrm{~m}, 2.366$ $\mathrm{rad} / \mathrm{s}, 0.376 \mathrm{~Hz}$, and $2.6556 \mathrm{~s}$. So using equation three obtained the spring constant is $397.4549 \mathrm{~N} / \mathrm{m}$.

For the results of legal analysis of conservation of energy on the harmonic motion can be seen from Figure 5.

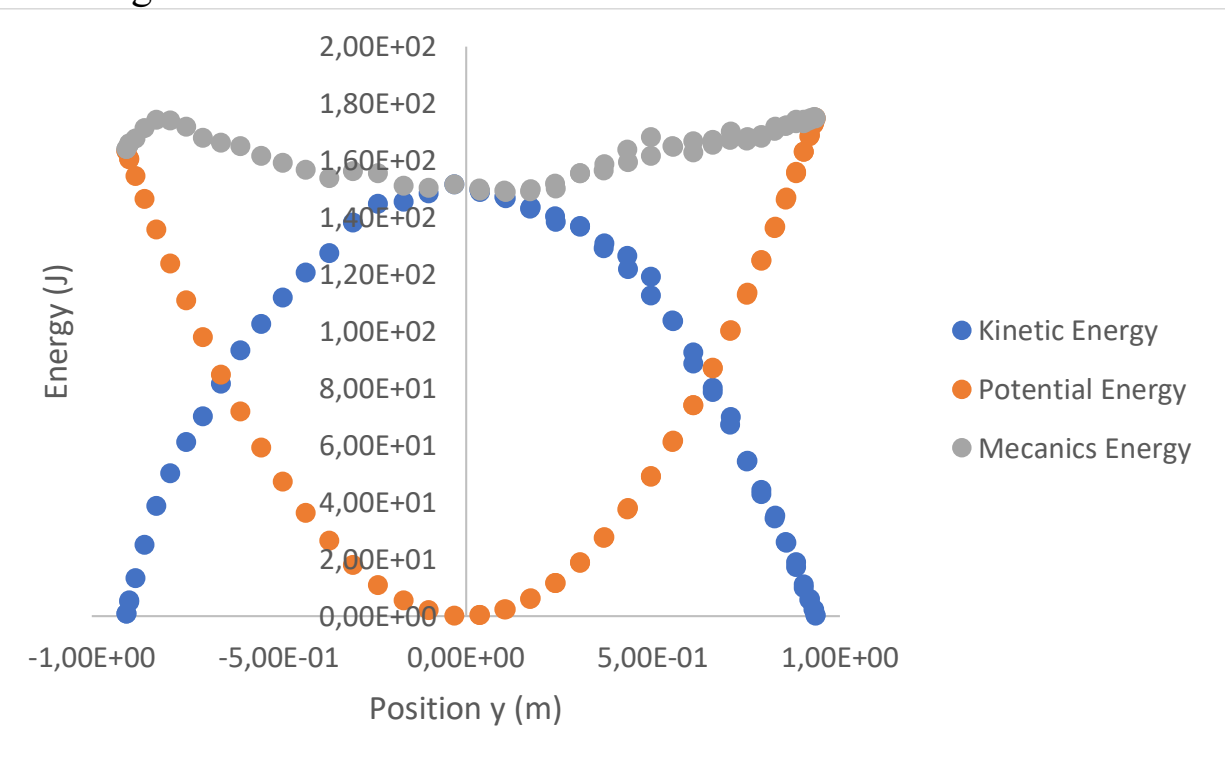

Figure 5. Graphed of the relationship between position (y) with energy

In Figure 5 it is clear that the law of conservation of harmonic energy of the trampoline rides is valid. It can be concluded that the concept of harmonic motion prevails in the amusement park of a trampoline. Evident from the results of the analysis using video tracking method in can kinematics value on the harmonic motion and energy conservation law on the trampoline rides is valid to apply.

With this result, if it can give an idea that learning physics can be fun while playing, and recreation (Fun Physics). Using this kind of learning model (Outdoor Physics) can undoubtedly erode students a sense of saturation in the study of physics. Indeed nature is a giant physics laboratory and the real physics laboratory. So it should be physics 
learning can connect between concepts and real examples in everyday life, because learning physics can be done anywhere and anytime.

\section{References}

[1] M. T. Natividad and V. M. Mistades, "Physics in an Amusement Park: The Experience of University Students," International Journal of Learning and Development, vol. 2, pp. 80-84, 2012.

[2] j. wiese, Amusement Park Physics, canada: science plus, 2016.

[3] Kusuma Agrowisata Group, "Wahana," [Online]. Available: http://www.kusumaedupark.com/?page=wahana. [Accessed 24 Juni 2017].

[4] M. Löfstrand and A. M. Pendrill, "Aerodynamics in the amusement Park: Interpreting sensor data for acceleration and rotation," IOP Science, 2016.

[5] M. C. Oliveira and S. Napoles, "Using a Spreadsheet to Study the Oscillatory Movement of a Mass-Spring System," Spreadsheets in Education, vol. 3, no. 3, pp. 1-23, July 2010.

[6] J. Poonyawatpornkul and P. Wattanakasiwich, "High-speed video analysis of Damped Harmonic Motion," IOP Science, vol. 48, pp. 782-789, November 2013.

[7] J. A. Bryan, "Investigating the Conservation of Mechanical Energy Using Video Analysis: Four Cases," IOP Science, vol. 45, pp. 50-57, January 2010.

[8] B. K. Temiz and A. Yuvuz, "Analysing Harmonic Motions With an iPhone's Magnetometer," IOP Science, vol. 51, pp. 1-6, May 2016.

[9] S. A. Brittle and T. H. Richardson, "Physical Pendulum Experiments to Enhance the Understanding of Moments of Inertia and Simple Pendulum Motion," IOP Science, vol. 47, pp. 537-544, September 2012.

[10] D. Eager and A. M. Pendrill, "Free Fall and Harmonic Oscillations: Analyzing Trampoline Jumps," IOP Science, vol. 50, pp. 64-70, January 2015. 